\title{
Investment Decision Analysis for Public Art Exhibitions
}

\author{
Wu Wen Tsung*, Chie-Bein Chen \\ Department of International Business, National Dong Hwa University, Taiwan
}

Copyright $(2016$ by authors, all rights reserved. Authors agree that this article remains permanently open access under the terms of the Creative Commons Attribution License 4.0 International License

\begin{abstract}
In recent years, China's growing cultural industry has significantly enhanced the region's cultural level and recognized public art and continues to develop the creative industry in various Chinese cities (except Beijing, Shanghai, and Canton). Through large-scale international public art exhibitions, each city in China intends to increase its cultural competitiveness, establish an image, and develop its cultural tourism industry and cross-border cultural exchange. By doing so, they hope to produce a combined movement toward creating a sustainable cultural art industry. This study examines the strategies undertaken to conduct the exhibition for the public art installation, the Rubber Duck, by Florentijn Hofman. In particular, it focuses on Hofman's Chinese agencies and the exhibition organizers in the city of Hangzhou and investigates whether random public art indicators influence the estimated effects prior to the exhibition and if there are actual benefits after the exhibition. This study evaluates profits and investments using net present value, internal rate of return, and game options. An analysis of existing mathematical models reveals that such models can provide analytical results across varying time periods. The results of the present model can help decide whether one should invest or turn down an exhibition in a given city.
\end{abstract}

Keywords Public Art, Game Option, Decision Evaluation, Wetland Hofman Rubber Duck

\section{Introduction}

\subsection{Object of Research}

In recent years, China's growing cultural industry has significantly enhanced the region's cultural level and recognized public art and continues to develop the creative industry in various Chinese cities (except Beijing, Shanghai, and Canton). Through large-scale international public art exhibitions, each city in China intends to increase its cultural competitiveness, establish an image, and develop its cultural tourism industry and cross-border cultural exchange. By doing so, they hope to produce a combined movement toward creating a sustainable cultural art industry. Florentijn Hofman's public art installation, the Rubber Duck, has been travelling around the globe since 2007 and gained much popularity across Asia in 2013. One of the locations on its travel map was Mainland China, which has known to be open to contemporary public art. A cultural industry can affect an economy's growth and development and one of the innovations within this sector is the exhibition industry.

\subsection{Literature Review}

The development of the exhibition industry has significantly affected Mainland China's economic growth and its use of internet-based technologies [1]. One of the objectives of exhibition development is to closely collaborate with local industries across various cities [2]. Public art provides a wide range of opportunities in the exhibition and tourism industries. For instance, the focus of an exhibition organizer is to develop an "exhibition city." Hartmann and Hassan[3] applied the real options approach to analyze the manufacturing industry within a more flexible strategy selection. Whitfield, Dioko, Webber, and Zhang[4] noted that an exhibition organizer helps develop and provide facilities and services beneficial for participants. One of the key factors they highlight is how a city's reaction to investment strategies can affect its potential value and project costs [5]. Thornton, Romley, Vogt, and Philipson[6] stated that a cost effectiveness analysis refers to the root value. This research explores the potential value of cities from the viewpoint of public art exhibitions. Espinoza and Rojo[7] used net present value (NPV) to estimate investments in the energy sector. Drawing on their study, this research uses NPV along with the internal rate of return (IRR) to evaluate the profits from and investments in exhibitions. In the NPV analysis of game options, the exhibition organizers and exhibition cities participate in a game model in which the profits obey the geometric Brownian motion (GBM). We create the formulae using value matching and accordingly, identify the optimal timing for exhibition organizers to invest in Mainland China's market. The results suggest that when competing exhibition cities are willing to host the same exhibition but face certain situations, which will be later discussed in this study, exhibition organizers are 
in a position to make a more informed decision regarding the optimal time to invest.

\section{Model}

This model explores expectations regarding the investment and entry strategies for the Rubber Duck exhibition in each city in Mainland China. It uses resources from the Rubber Duck tour in Mainland China's Hangzhou city and the NPV data by FPG Taiwan International Ltd. Combining these resources with the mathematical model can help evaluate the potential value generated from future payoffs and cities can accordingly make an informed decision regarding holding an exhibition that falls under the Rubber Duck exhibition plan. The findings of this model can have implications regarding an optimal entry strategy for exhibition organizers and cities looking to host such exhibitions.

The model comprises three companies involved in the Rubber Duck tour in the city of Hangzhou. First is FPG Taiwan International Ltd. (notation F), although it obtained the Rubber Duck tour through the authorization of Mainland China, which was initially acquired by Florentijn Hofman. Second is Chzhixing's advertising company (notation O), which was the organizer for the Rubber Duck exhibition. Finally, Hangzhou's Xixi Wetland National Park (notation C) served as the exhibition city.

Chzhixing advertising company was keen to invest in the Rubber Duck exhibition in Mainland China. At the same time, the Xixi Wetland National Park was interested in organizing the 2014 International Dragon Boat Race Arts Festival. Thus, Chzhixing drafted a proposal to FPG Taiwan International Ltd, although it took two months for the exhibition organizers to acquire the necessary authorizations, including signing of the contract, framing of the main exhibition, and imports and exports. Although, the application did not meet the requirements, the proposal clearly showed that the Xixi Wetland National Park was an attractive place and had potential. FPG Taiwan International Ltd., therefore, accepted the application one month prior to the exhibition.

Chzhixing used the past number of visitors to the Xixi Wetland National Park to estimate daily visitor numbers (20,000 persons per day). They then multiplied this number by 45 days, leaving them with an expected number of 90 million visitors to the Rubber Duck exhibition in Hangzhou. However, the expected number of visitors needed to be reduced by 18 million persons as per the commission obtained from the imposed barrier. Moreover, the Rubber Duck exhibition had gained much popularity across Asia, giving Chzhixing advertising company the opportunity to earn revenue from Rubber Duck merchandise, in addition to the mentioned ticket commission.

On May 9, 2014, FPG Taiwan International Ltd. reached an agreement with Chzhixing advertising company regarding the Rubber Duck tour in Hangzhou. The exhibition was slated for the period between June 15, 2014, and July 15, 2014. However, because the 2014 International Dragon Boat Race Arts Festival was already scheduled from May 31, 2014, to June 2, 2014, Chzhixing advertising company requested for an extension for the Rubber Duck exhibition from FPG Taiwan International Ltd. Since Hangzhou was the first venue for the Rubber Duck tour in Mainland China, FPG Taiwan International Ltd. accepted the extension request, although Chzhixing had to bare an extension fee.

\subsection{Net Present Value for Exhibition Organizers and Exhibition Cities}

This model uses NPV and IRR to estimate the profits from and investments in the Rubber Duck tour in Mainland China's Hangzhou city. Most past research evaluate project value using static investment conditions; however, the present model uses dynamic project values to calculate these factors at every stage of the exhibition. The findings from the model can provide exhibition organizers and cities wanting to host such an exhibition with a more accurate estimation of the appropriate time to invest in the Rubber Duck exhibition. First, the model uses the NPV method to analyze the project and related planning strategies. Then, it compares the estimated NPV with the expected net present value (ENPV) to help make an informed project investment decision [8].

We make several assumptions in terms of value and the costs are perfectly competitive. Since the cost does not include taxes, the trend may differ by period, although the cost movement is made available for all stages. The exhibition is mainly divided into $T$ fixed periods. $V_{u}$ and $V_{d}$ denote the upward and downward movement of cost.

This model applies the binomial options pricing model to calculate the Rubber Duck exhibition, which is based on the risk-neutral pricing method. Next, it uses the upward and downward movements and IRR to calculate the two probabilities of $\mathrm{P}$ and $(1-\mathrm{P})$. We assume that $\mathrm{u}>1, \mathrm{~d}<1$, $\mathrm{u}>1+\mathrm{rf}>\mathrm{d}$, and $\mathrm{u}=1 / \mathrm{d}$.

$\mathrm{V}_{\mathrm{u}}$ is the ENPV for the exhibition organizer in Hangzhou and $V_{d}$ is the actual NPV. $V_{0}$ is the input cost for the exhibition organizer and $\mathrm{K}$ is the discount rate.

$$
\mathrm{V}_{0}=\frac{\left(0.5 \times V_{u}\right)+\left(0.5 \times V_{d}\right)}{(1+K)}
$$

Accordingly, the cost incurred to organize the Rubber Duck exhibition organizer in Hangzhou is 7,000,000 RMB. Therefore, the discount rate is $5 \%$ and was the discount an average lending rate for Taiwan's banks. We may assume this to be the risk premium in the investment stage of the exhibition. 


\subsection{Optimal Timing for Exhibition Organizer and Exhibition City}

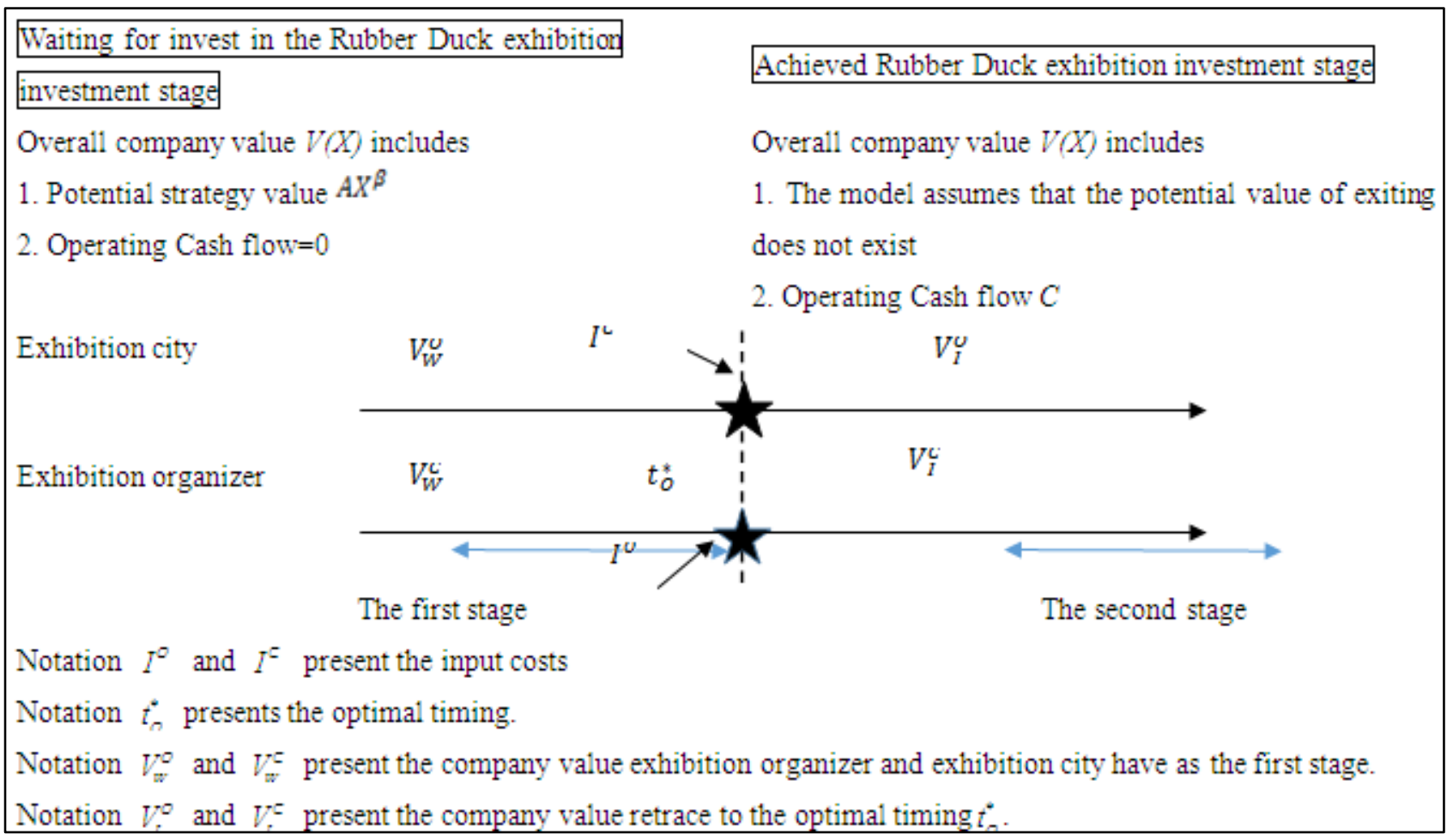

Figure 1. Decision Making Model for the Exhibition Organizer and Exhibition City Searching for the Best Investment Time for the Rubber Duck Exhibition Invention

Using the NPV and ENPV (Section 2.1) and the number of expected visitors, which follows the GBM, we evaluate the optimal time for exhibition organizers and exhibition cities to conduct the Rubber Duck exhibition. The model has two major stages: waiting to invest and successfully investing. First, the exhibition organizer and exhibition city enter the Mainland China exhibition market. At this point, the exhibition organizer and exhibition city are waiting to invest in the Rubber Duck exhibition. At optimal timing $t_{O}^{*}$, the exhibition organizer and exhibition city invest in Mainland China's exhibition market to form a duopoly in the investment stage.

\subsection{Waiting to Invest Stage}

In the waiting to invest stage for the exhibition organizer, $V_{W}^{O}\left(X_{t}\right)$ is the company value in the first stage of the model. Since there is no cash flow in this stage of the model, capital gain $A_{O} X_{t}^{\beta_{O}}$ is composed of the company value of the exhibition organizer, which can be used for future investments and denotes the company value at the unit time for the waiting to invest stage. Coefficient $\beta_{O}$ is used to calculate the risk neutral condition, $\beta_{O}>0 . A_{O}$ is the scale factor to determine the potential strategic value. The functions are as follows:

$$
V_{W}^{O}\left(X_{t}\right)=A_{O} X_{t}^{\beta_{O}}
$$

$$
\beta_{O}=\frac{\left(\frac{1}{2} \sigma^{2}-\mu\right) \pm \sqrt{\left(\mu-\frac{1}{2} \sigma^{2}\right)^{2}+2 r_{0} \sigma^{2}}}{\sigma^{2}}
$$

$r_{0}$ is the risk premium (discounted rate).

During the waiting to invest stage for the exhibition city, $V_{W}^{C}\left(X_{t}\right)$ is the company value during the first stage of the model. Here as well, since there is no cash flow in this stage, the capital gain $A_{C} X_{t}^{\beta_{L}}$ is composed of the company value for the exhibition city, which can be used for future investments, and represents the company value at the unit time in the waiting to invest stage. Coefficient $\beta_{C}$ is used to calculate the risk neutral condition, $\beta_{C}>0 . A_{C}$ is the scale factor used to determine the potential strategic value. The functions are as follows:

$$
\begin{gathered}
V_{W}^{C}\left(X_{t}\right)=A_{C} X_{t}^{\beta_{C}} \\
\beta_{C}=\frac{\left(\frac{1}{2} \sigma^{2}-\mu\right) \pm \sqrt{\left(\mu-\frac{1}{2} \sigma^{2}\right)^{2}+2 r_{0} \sigma^{2}}}{\sigma^{2}}
\end{gathered}
$$

$r_{0}$ is the risk premium (discounted rate).

\subsection{Company Value at the Successfully Investing Stage}

The exhibition organizer input costs associated with 
investments is denoted by $I^{O}$, with $t_{O}^{*}$ being the optimal time to invest. Therefore, if the exhibition organizer has invested, we assume that $V_{I}^{O}\left(X_{t}\right)$, the company value for the exhibition organizer, retraces to optimal time $t_{O}^{*}$ in the second stage of the model. Since, in this study, we assume there are no strategic changes after the investment has taken place, no capital gains exist during the successfully investing stage. Cash flow $C_{I}^{O}\left(X_{t}\right)$ is composed of the company value for the exhibition organizer and that for the unit time in the successfully investing stage. $r_{H}$ refers to the risk premium (discount rate) once the investment has taken place. The function is as follows:

$$
V_{I}^{H}\left(X_{t}\right)=C_{I}^{H}\left(X_{t}\right)
$$

The exhibition organizer's input costs associated with investment in denoted by $I^{C}$ and $\boldsymbol{t}_{C}^{*}$ is the optimal time to invest. Therefore, we can assume that the exhibition organizer has successfully invested in the exhibition and $V_{I}^{C}\left(X_{t}\right)$ is the company value of the exhibition city, which retraces to the optimal time $t_{C}^{*}$ in the second stage of model. Since we assume no strategic changes after the investment, no capital gain exists during the successfully investing stage. Cash flow $C_{I}^{L}\left(X_{t}\right)$ is composed of the company value for the exhibition city and that for the unit time in the successfully investing stage. $r_{C}$ refers to the risk premium (discount rate) once the investment has taken place. The function is as follows:

$$
V_{I}^{C}\left(X_{t}\right)=C_{I}^{C}\left(X_{t}\right)
$$

Accordingly, the assumed input costs $I^{O}$ and $I^{C}$ have positive linear relationships with the expected number of visitors. Threshold $y$ is the cost of the required inputs for each visitor and $z$ is other input costs incurred for the exhibition, such as contract, authorization, facilities, catering, and personnel costs. Therefore, the participants exhibition organizer and exhibition city in the model can be represented by $y>y^{\prime}$ and $z>z^{\prime}$. The functions are as follows:

$$
\begin{gathered}
I^{n}=y\left(X_{t}\right)+z \\
I^{n}=y^{\prime}\left(X_{t}\right)+z^{\prime}
\end{gathered}
$$

Then, the assumed cash flows $C_{I}^{o}\left(X_{t}\right)$ and $C_{I}^{C}\left(X_{t}\right)$ in the model have positive linear relationships with the expected number of visitors. Threshold $a$ refers to the operating net value profit gained from each visitor and $b$ is other operating net value profits gained from the visitors, including dining, facilities, and profits from merchandise. Among the model's participants, the exhibition organizer is the leader and forms a monopoly in the second stage and a duopoly in the future investment stage. The exhibition organizer's cash flow in the second stage will be more than that in the future investment stage. $C_{I}^{o}\left(X_{t}\right)<C_{I}^{o}\left(X_{t}\right)$ shows that higher inputs can produce higher income value. For example, the exhibition organizer can earn higher profits than the exhibition city, which is represented as $a>a^{\prime}>a^{\prime \prime}$ and $b>b^{\prime}>b^{\prime \prime}$. The exhibition city, thus, becomes the leader and forms a monopoly in the second stage and a duopoly in the future investment stage. The exhibition city's cash flow in the second stage will be more than that in the future investment stage. In this case, $C_{I^{\prime}}^{C}\left(X_{t}\right)<C_{I}^{C}\left(X_{t}\right)$ shows that the exhibition city is the leader with input investment and profits higher than those of the exhibition organizer, which is represented by $a^{\prime \prime}>a>a^{\prime}$ and $b^{\prime \prime}>b>b^{\prime}$.

The functions are as follows:

$$
\begin{array}{r}
C_{I}^{O}\left(X_{t}\right)=a\left(X_{t}\right)+b \\
C_{I^{\prime}}^{O}\left(X_{t}\right)=a^{\prime}\left(X_{t}\right)+b^{\prime} \\
C_{I}^{C}\left(X_{t}\right)=a^{\prime \prime}\left(X_{t}\right)+b^{\prime \prime}
\end{array}
$$

and

$$
\begin{aligned}
& C_{I}^{L}\left(X_{t}\right)=a\left(X_{t}\right)+b \\
& C_{I^{\prime}}^{L}\left(X_{t}\right)=a^{\prime}\left(X_{t}\right)+b^{\prime} \\
& C_{I}^{H}\left(X_{t}\right)=a^{\prime \prime}\left(X_{t}\right)+b^{\prime \prime}
\end{aligned}
$$

and

$$
\begin{gathered}
C_{I}^{H}\left(X_{t}\right)=a\left(X_{t}\right)+b \\
C_{I}^{L}\left(X_{t}\right)=a^{\prime}\left(X_{t}\right)+b^{\prime}
\end{gathered}
$$

\subsection{Decision Threshold Value}

Here, we use the GBM condition and the value-matching and smooth-pasting conditions [9] to identify the optimal timing on the basis of the expected visitor threshold to invest in the exhibition for the two participants in the model:

$$
t_{O}^{*}=\left[\frac{1}{\mu}\right] \log \left[\frac{E\left[X_{t_{O}^{*}}\right]}{X}\right]
$$

A. Value-matching condition [9]: The exhibition organizer and exhibition city's value for the optimal timing is the same, $t_{O}^{*}$. The aggregate of the capital gain for the exhibition organizer in the first stage and the input cost $I^{O}$ equals the cash flow in the second stage, which retraces to optimal time $t_{O}^{*}$. At the same optimal time $t_{O}^{*}$, the capital gain for the exhibition city in the first stage plus input cost $I^{C}$ equals the cash flow in the second stage, which 
retraces to optimal time $t_{O}^{*}$ for the exhibition organizer and exhibition city.

$$
\begin{aligned}
& A_{O}\left(E\left[X_{t_{O}^{*}}\right]\right)^{\beta_{O}}+\mathrm{I}^{O}\left(X_{t_{O}^{*}}\right)=E\left[\int_{t_{O}^{*}}^{\infty} e^{-r_{O}\left(t-t_{O}^{*}\right)} C_{I}^{O}\left(X_{t}\right) d t\right] \\
& A_{C}\left(E\left[X_{t_{O}^{*}}\right]\right)^{\beta_{C}}+\mathrm{I}^{L}\left(X_{t_{O}^{*}}\right)=E\left[\int_{t_{O}^{*}}^{\infty} e^{-r_{L}\left(t-t_{O}^{*}\right)} C_{I}^{L}\left(X_{t}\right) d t\right]
\end{aligned}
$$

B. Smooth-pasting condition [9]: Equation (19) is used to estimate the first-order differentials at optimal time $t_{H}^{*}$ using the value-matching formula.

$$
\frac{A_{O}\left(E\left[X_{t_{O}^{*}}\right]\right]^{\beta_{O}}+\mathrm{I}^{H}\left(X_{t_{O}^{*}}\right)}{d t_{O}^{*}}=\frac{E\left[\int_{t_{O}^{*}}^{\infty} e^{-r_{O}\left(t-t_{O}^{*}\right)} C_{I}^{O}\left(X_{t}\right) d t\right]}{d t_{O}^{*}}
$$

The exhibition organizer and exhibition city invest at the same optimal time $t_{O}^{*}$. The advantage of doing so is that the value-matching and smooth-pasting conditions will also be the same. Thus, Equation (26) also shows a smooth-pasting condition when the exhibition organizer and exhibition city invest at the same optimal time $t_{O}^{*}$.

By adding the input cost from Equation (8) and cash flow from Equation (16), which assume positive linear relationships with the expected tourist numbers, the value-matching conditions can be obtained as follows:

$$
\begin{gathered}
A_{O}\left(X_{0}\right)^{\beta_{O}} e^{k \cdot t_{O}^{*}}+y \cdot X_{0} e^{\mu \cdot t_{O}^{*}}+z \\
=\left(a X_{0} e^{r_{O} \cdot t_{O}^{*}}\right)\left[\frac{1}{\left(r_{O}-\alpha\right)}\left(e^{\left.-\left(r_{O}-\alpha\right)\right)_{O}^{*}}\right)\right]+\left(b^{n} e^{r_{O} \cdot t_{O}^{*}}\right)\left[\frac{1}{r_{O}}\left(e^{-r_{O} \cdot t_{O}^{*}}\right)\right] \\
k=\beta_{O}\left[\left(\mu-\frac{1}{2} \sigma^{2}\right)+\left(\beta_{O}\right)^{2} \cdot \frac{1}{2} \sigma^{2}\right]
\end{gathered}
$$

By adding the input cost from Equations (9) and cash flow from Equation (17), which assume positive linear relationships with the expected tourist numbers, the value-matching conditions can be obtained as follows:

$$
\begin{gathered}
A_{C}\left(X_{0}\right)^{\beta_{C}} e^{d \cdot t_{O}^{*}}+y^{\prime} \cdot X_{0} e^{\mu \cdot t_{O}^{*}}+z^{\prime} \\
=\left(a^{\prime} X_{0} e^{r_{C} \cdot t_{O}^{*}}\right)\left[\frac{1}{\left(r_{C}-\alpha\right)}\left(e^{-\left(r_{C}-\alpha\right) t_{O}^{*}}\right)\right]+\left(b^{\prime} e^{r_{C} \cdot t_{O}^{*}}\right)\left[\frac{1}{r_{C}}\left(e^{-r_{C} \cdot t_{O}^{*}}\right)\right] \\
d=\beta_{C}\left[\left(\mu-\frac{1}{2} \sigma^{2}\right)+\left(\beta_{C}\right)^{2} \cdot \frac{1}{2} \sigma^{2}\right]
\end{gathered}
$$

By adding the input cost from Equation (8) and cash flow from Equation (16), which assume positive linear relationships with the expected visitor numbers, the smooth-pasting conditions can be obtained as follows:

$$
\begin{aligned}
& k \cdot A_{O}\left(X_{0}\right)^{\beta_{O}} e^{k \cdot t_{O}^{*}}+\mu \cdot y \cdot X_{0} e^{\mu \cdot t_{O}^{*}} \\
& -\left\{\left(a X_{0}\right)\left[\left(\frac{r_{O}}{\left(r_{O}-\alpha\right)}-1\right)\left(e^{\alpha t_{O}^{*}}\right)\right]\right\}=0
\end{aligned}
$$

A. Value-matching condition [9]: The exhibition organizer and exhibition city's value for the optimal timing is the same. Therefore, at the same optimal timing $t_{O}^{*}$, the capital gain for the exhibition organizer in the first stage plus input cost $I^{O}$ equals the cash flow in the second stage, which retraces to optimal time $t_{O}^{*}$. At the same optimal timing $t_{O}^{*}$, the capital gain for the exhibition city in the first stage plus the input cost $I^{C}$ equals the cash flow in the second stage, which retraces to optimal time $t_{O}^{*}$.

$$
A_{O}\left(E\left[X_{t_{O}^{*}}\right]\right)^{\beta_{O}}+\mathrm{I}^{O}\left(X_{t_{O}^{*}}\right)=E\left[\int_{t_{O}^{*}}^{\infty} e^{-r_{O}\left(t-t_{O}^{*}\right)} C_{I}^{O}\left(X_{t}\right) d t\right]
$$

$$
A_{O}\left(E\left[X_{t_{O}^{*}}\right]\right)^{\beta_{C}}+\mathrm{I}^{C}\left(X_{t_{O}^{*}}\right)=E\left[\int_{t_{O}^{*}}^{\infty} e^{-r_{C}\left(t-t_{O}^{*}\right)} C_{I}^{C}\left(X_{t}\right) d t\right]
$$

B. Smooth-pasting condition [9]: Equation (19) is used to obtain the first-order differentials at optimal time $t_{H}^{*}$ using the value-matching formulae.

$$
\frac{A_{O}\left(E\left[X_{t_{O}^{*}}\right]\right)^{\beta_{O}}+\mathrm{I}^{O}\left(X_{t_{O}^{*}}\right)}{d t_{O}^{*}}=\frac{E\left[\int_{t_{O}^{*}}^{\infty} e^{-r_{O}\left(t-t_{O}^{*}\right)} C_{I}^{O}\left(X_{t}\right) d t\right]}{d t_{O}^{*}}
$$

\section{Numerical Example of the Model}

Using the Rubber Duck exhibition in the city of Hangzhou, Mainland China, as a case study, this research adopted a mathematical decision-making model with the value-matching and smooth-pasting conditions to clarify and recognize the optimal timing for future investments for the exhibition organizer and city. The model is calculated using POLYMATH software. It assumes that the data are suitable for the model. Equations (22) and (24) show the value-matching conditions and Equation (26) is the smooth-pasting conditions in the model.

Using POLYMATH software, we were able to derive the same optimal timing for the exhibition organizer and exhibition city, which expands at the same time as the scale 
factors, to determine the potential strategic value for both (Table 1). Table 2 represents the assumptions of the relevant parameters in the model. From the parameter values, we calculated that the number of expected visitors is
20,634 at the optimal time $t_{O}^{*}$, which is the optimal opportunity for both the exhibition organizer and exhibition city to invest.

Table 1. Notation and Parameter Values of the Model

\begin{tabular}{|c|c|c|}
\hline Variable & Notation & Parameter Value \\
\hline The average growth rate of the number of visitors & $\mu$ & 0.09 (per year) \\
\hline Volatility growth rate of the number of visitors & $\sigma$ & 0.9 (per year) \\
\hline Risk premium at waiting for doing exhibition invention stage & $r_{0}$ & 0.5 \\
\hline Risk premium at the achieved exhibition invention stage of the exhibition city & $r_{C}$ & 0.4 \\
\hline Risk premium at the achieved exhibition invention stage of the exhibition organizer & $r_{O}$ & 0.5 \\
\hline Initial value of the number of visitors & $X_{0}$ & 17500 (10,000 unit) \\
\hline Input costs for the exhibition organizer & $y$ & 35000000 \\
\hline Input costs for the exhibition city & $y^{\prime}$ & 8750000 \\
\hline Fixed input costs for the exhibition organizer & $z$ & 105000000 \\
\hline Fixed input costs for the exhibition city & $z^{\prime}$ & 17500000 \\
\hline Cash flow of the exhibition organizer in the next stage & $a$ & 21000000 \\
\hline Cash flow of the exhibition city in the next stage & $a^{\prime}$ & 14000000 \\
\hline Fixed cash flow of the exhibition organizer in the next stage & $b$ & 0 \\
\hline Fixed cash flow of the exhibition city in the next stage & $b^{\prime}$ & 0 \\
\hline
\end{tabular}

Table 2. Numerical Analysis of the Model

\begin{tabular}{|c|c|c|c|}
\hline Threshold and Potential Value & $A_{O}$ & $A_{C}$ & $t_{O}^{*}$ \\
\hline Solution & 3684164 & 3113444 & 0.77 \\
\hline
\end{tabular}




\section{Conclusions}

This study broadly discussed the Rubber Duck tour in the city of Hangzhou, Mainland China, and the optimal time to invest in such an event on the basis of the number of visitors using the GBM, NPV, and IRR. The findings suggested that high expectations from the tour largely led to reduced investments; however, despite this, we were able to calculate the potential profits from and the optimal timing to invest in the event. In this study, we presented a mathematical formula that has implications for future inventors in the Rubber Duck tour in China and information-based index for exhibition organizers in general.

\section{REFERENCES}

[1] C. Butler, Y. Bassiouni, M. El-Adly, A. Widjaja. Revamping the value chain in exhibition facilities: the case of the Dubai exhibition industry, Facilities. Vol. 25, No. 11/12, 419-436, 2007.

[2] X. Jin, K. Weber, T. Bauer. Impact of clusters on exhibition destination attractiveness: evidence from Mainland China, Tourism Management. Vol. 33, No. 6, 1429-1439, 2012.

[3] Hartmann, Hassan, 2006
[4] J. Whitfield, L. D. A. Dioko, D. Webber, L. Zhang. Attracting convention and exhibition attendance to complex MICE venues: emerging data from Macao, International Journal of Tourism Research. Vol. 16, No. 2, 169-179, 2014

[5] Watkiss, Hunt, Blyth, Dyszynski, 2014

[6] J. Thornton Snider, J. A. Romley, W. B. Vogt, T. J. Philipson. The option value of innovation, Forum for Health Economics \& Policy. Vol. 15, No. 2, 1-19, 2012.

[7] R. D. Espinoza, J. Rojo. Using DNPV for valuing investments in the energy sector: a solar project case study, Renewable Energy. Vo. 75, No. 4, 44-49, 2015.

[8] R. C. Merton. Theory of rational option pricing, The Bell Journal of Economics and Management Science. Vol. 4, No. 1,141-183, 1973.

[9] A. Dixit, Entry and exit decisions under uncertainty, Journal of Political Economy. Vol. 97, No. 3, 620-638, 1989.

[10] J. Clark, A. Kearns. People, Place and Prosperity in the East End of Glasgow: An Assessment of the Potential Economic Impacts of the 2014 Commonwealth Games and Associated Regeneration Activities on Local Communities, GoWell, 2014.

[11] Y. Qiu, Y. D. Wang, J. Wang. Implied discount rate and payback threshold of energy efficiency investment in the industrial sector, Applied Economics. Vol. 47, No. 21, 2218-2233, 2015 